\title{
NIAGARA METEORITE.
}

In the winter of I 900 I was informed by Mr. Vennor, a young mineral collector of Rochester, N. Y., that he had seen in the possession of one of his friends, now living in this city, what he supposed to be a small iron meteorite, which had been picked up on a ranch in North Dakota, some years before. After some persuasion Mr. Vennor succeeded in getting his friend to permit me to examine the specimen, which I saw at a glance was a meteorite with marked octahedral cleavage where it had been broken, and finally purchased it for Ward's Natural Science establishment.

This meteorite, which belongs to the siderite class, was found two miles southeast of Niagara, Forks county, N. D., in the early part of August, I879, by Mr. F. Talbot, the son of the lady from whom Mr. Vennor obtained it for me. Mr. Talbot was making a collection of the various rocks and minerals in his neighborhood, and in his search for these discovered the above meteorite on the ranch owned by his father. As Mr. Talbot has since passed away, the specimen had been retained in his family rather as a keepsake in remembrance of him than as a visitor from outer space.

When I received the meteorite it weighed II 5 grams and was about $30 \times 40 \times 50^{\mathrm{mm}}$ in dimensions. It was very much oxidized, of a brownish-black color, and showed no trace of the original crust whatever. In sawing it we succeeded in getting but three sizeable pieces, as it crumbled into small fragments from 2 to 4 or 5 grams in weight in cutting. The largest piece obtained of the unoxidized iron suitable for etching weighed 26 grams and is now in the Ward-Coonley collection of meteorites. The only other piece suitable for etching weighed I 7 grams and is in the British Museum collection. The largest fragment from the crumbled portion of the iron was a fairly good tetrahedron, $24 \times 23 \times 15^{\mathrm{mm}}$ in its greatest diame- 
ters, and weighed 18 grams. This fragment showed bright plates of taenite on two of its cleaved faces. This feature was likewise shown on a number of the smaller fragments.

On etching the two pieces composed of the unoxidized iron, its octahedral structure was strongly marked in the Widmanstätten figures, the kamacite plates being somewhat broad with a second series of markings of hair-like lines upon them about the size of the Neumann lines on the Braunau iron.

Mr. J. M. Davison, of the Reynolds Laboratory of the University of Rochester, kindly made the analysis of this meteorite for me, and found it to be composed of

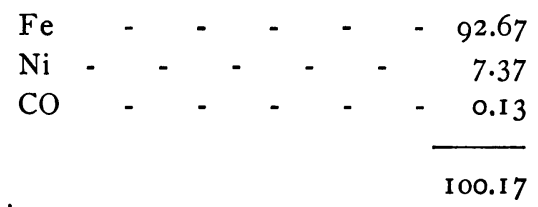

Specific gravity 7.12.

From its close proximity to Niagara, we will designate the siderite the Niagara, Forks county, N. Dakota Meteorite.

H. L. Preston.

ROCHESTER, N. Y. 